\title{
The Decline and Fall of the Cardiac Biomarker: A Good Indicator of Resolution of Cardiac Dysfunction following Perinatal Asphyxia
}

\author{
Commentary on D.C. Vijlbrief et al.: Cardiac Biomarkers as Indicators of \\ Hemodynamic Adaptation during Postasphyxial Hypothermia Treatment \\ (Neonatology 2012;102:243-248)
}

\section{Eleanor J. Molloy}

Paediatrics, National Maternity Hospital, Paediatrics, Royal College of Surgeons of Ireland, Neonatology, Our Lady's Children's Hospital, Crumlin, and UCD School of Medicine and Medical Sciences, University College Dublin, Dublin, Ireland

Neonatal asphyxia induces global hypoxia-ischaemia resulting in multi-organ injury [1]. Cardiac, renal, hepatic and haematological dysfunction are well-described. Martín-Ancel et al. [2] found that $29 \%$ of neonates with perinatal asphyxia had cardiac dysfunction consistent with myocardial ischaemia.

Hypothermia is the latest treatment for neonatal brain injury following perinatal asphyxia to come into widespread use [3]. Infants with perinatal asphyxia treated with hypothermia have decreased biventricular function and coronary artery flow and significantly elevated troponin compared with normal term control infants [4]. In addition the cardiac biomarker cardiac troponin I (cTnI) and pathological cardiac lesions are significantly reduced after hypothermia treatment in hypoxic-ischaemic newborn pigs [5]. Hypothermia has a direct cardioprotective role and reduces cardiomyocyte injury after oxidative stress in animal models [6]. However, the effect of hypothermia on cardiac biomarkers has not been extensively investigated in human newborns.

The paper 'Cardiac biomarkers as indicators of hemodynamic adaptation during postasphyxial hypothermia treatment' by Vijlbrief et al. [7] reports an observational cohort study of infants treated with mild hypothermia following perinatal asphyxia. They investigated whether hypothermia exerts a beneficial effect on the heart after perinatal asphyxia using the cardiac biomarkers $\mathrm{cTnI}^{\mathrm{T}}$ and brain natriuretic peptide (BNP). Troponin $\mathrm{T}$ and I are sensitive markers of myocardial injury following a perinatal hypoxic-ischaemia insult. BNP is a marker of ventricular wall stress secondary to myocardial dysfunction [8]. cTnI and BNP were collected before the start of hypothermia, at 24 and $48 \mathrm{~h}$ after birth, and after rewarming. BNP was significantly lower in the infants who underwent hypothermia compared with historical controls with perinatal asphyxia but not treated with hypothermia. The authors did not see a difference in troponin levels in the 2 groups which normalised in both groups by $84 \mathrm{~h}$ of age. This study differed from other studies of neonatal cardiac dysfunction following perinatal asphyxia and hypothermia as comparison was made with historical controls with perinatal asphyxia rather than normal healthy controls. This may explain why the authors found decreased BNP and no difference in troponin in infants treated with hypothermia. This study is interesting as it shows that although following perinatal asphyxia troponin levels are very elevated they decline to normal levels in both groups by day 4 of life, which may indicate complete resolution of cardiac dysfunction.

Cardiac troponin T, cTnI and BNP are well-described markers of myocardial ischaemia and cardiac failure in adults, children and neonates [9]. BNP is released in re-

\section{KARGER \\ Fax +4161306 1234 \\ E-Mail karger@karger.ch}

www.karger.com
(C) 2012 S. Karger AG, Basel

$1661-7800 / 12 / 1024-0249 \$ 38.00 / 0$

Accessible online at:

www.karger.com/neo
Eleanor Molloy

Paediatrics, National Maternity Hospital

Holles Street

Dublin 2 (Ireland)

Tel. +353 1637 3100, E-Mail elesean@ hotmail.com 
sponse to volume and pressure loading and ventricular stress. Cardiac troponin I is released from myocytes in both reversible and irreversible myocardial injury. The changes in myocyte membrane permeability resulting from the injury could be enough for the release of cardiac troponins from the free cytosolic pool of myocytes without permanent structural damage. Both BNP and troponin are elevated in preterm infants with a significant patent ductus arteriosus and decrease with closure of the ductus $[10,11]$ and both have been used to evaluate the response to treatment of congenital heart disease [12]. BNP is elevated in persistent pulmonary hypertension of the newborn and correlates well with the pressure gradient across the tricuspid valve [13] and therefore may be a useful marker in infants with persistent pulmonary hypertension of the newborn following perinatal asphyxia. Cord blood BNP also significantly elevated in infants requiring inotropes with a range of diagnoses including a subgroup with perinatal asphyxia [14].

The paucity of echocardiography in many neonatal centres increases the importance of surrogate markers of cardiac dysfunction such as BNP, NTproBNP and troponin. Serial levels of these cardiac biomarkers could be used to evaluate the severity of cardiac compromise and responses to therapy such as inotropes without the need for constant echocardiography on a 24-hourly basis. In addition their potential as markers of longer-term cardiac function requires evaluation in conjunction with echocardiography. Point of care sampling of BNP and troponin would simplify their use in the neonatal intensive care unit as cardiac biomarkers and has been validated for this purpose [15]. Elevated troponin, NTpBNP (inactive by-product of the cleavage of ProBNP to BNP) at $48 \mathrm{~h}$ identifies preterm infants with a patent ductus arteriosus at greatest risk of death or poor 2-year neurodevelopmental outcome [11]. Therefore, although initial troponin levels normalize in many infants, the maximum troponin level may indicate the degree of perinatal asphyxia. Although evidence of cardiac dysfunction and injury is well-described following perinatal asphyxia, there is a need for cardiovascular as well as neurodevelopmental follow-up studies to see if this is a sustained effect that may have implications in later childhood or adulthood.

The advent of newer therapies such as xenon in combination with hypothermia may also improve cardiovascular outcomes as demonstrated in a neonatal piglet model of hypoxia-ischaemia [16]. Incorporating cardiac biomarkers in future neonatal clinical cardiovascular research may facilitate their use in routine clinical practice.

\section{References}

1 Shankaran S, Pappas A, McDonald SA, Vohr BR, Hintz SR, Yolton K, et al, Eunice Kennedy Shriver NICHD Neonatal Research Network: Childhood outcomes after hypothermia for neonatal encephalopathy. N Engl J Med 2012;366:2085-2092.

-2 Martín-Ancel A, García-Alix A, Gayá F, Cabañas F, Burgueros M, Quero J: Multiple organ involvement in perinatal asphyxia. J Pediatr 1995; 127:786-793.

-3 Shah P, Riphagen S, Beyene J, Perlman M: Multiorgan dysfunction in infants with postasphyxial hypoxic-ischaemic encephalopathy. Arch Dis Child Fetal Neonatal Ed 2004; 89:F152-F155.

-4 Liu X, Tooley J, Løberg EM, Suleiman MS, Thoresen M: Immediate hypothermia reduces cardiac troponin I after hypoxic-ischemic encephalopathy in newborn pigs. Pediatr Res 2011;70:352-356.

5 Sehgal A, Wong F, Mehta S: Reduced cardiac output and its correlation with coronary blood flow and troponin in asphyxiated infants treated with therapeutic hypothermia. Eur J Pediatr 2012, E-pub ahead of print.

6 Huang C-H, Chen H-W, Tsai M-S, Hsu C-Y, Peng R-H, Wang T-D, Chang W-T, Chen W-J: Antiapoptotic cardioprotective effect of hy- pothermia treatment against oxidative stress injuries. Acad Emerg Med 2009;16:872-880.

7 Vijlbrief DC, Benders MJNL, Kemperman $\mathrm{H}$, van Bel F, de Vries WB: Cardiac biomarkers as indicators of hemodynamic adaptation during postasphyxial hypothermia treatment. Neonatology, in press.

-8 Sweetman D, Armstrong K, Murphy JF, Molloy EJ: Cardiac biomarkers in neonatal hypoxic ischaemia. Acta Paediatr 2012;101: 338-343.

9 Armstrong K, Franklin O, Sweetman D, Molloy EJ: Cardiovascular dysfunction in infants with neonatal encephalopathy. Arch Dis Child 2012;97:372-375.

10 Sanjeev S, Pettersen M, Lua J, Thomas R, Shankaran S, L'Ecuyer T: Role of plasma Btype natriuretic peptide in screening for hemodynamically significant patent ductus arteriosus in preterm neonates. J Perinatol 2005;25:709-713.

11 El-Khuffash AF, Slevin M, McNamara PJ, Molloy EJ: Troponin T, N-terminal pro natriuretic peptide and a patent ductus arteriosus scoring system predict death before discharge or neurodevelopmental outcome at 2 years in preterm infants. Arch Dis Child Fetal Neonatal Ed 2011;96:F133-F137.
12 Mir TS, Haun C, Lilje C, Läer S, Weil J: Utility of N-terminal brain natriuretic peptide plasma concentrations in comparison to lactate and troponin in children with congenital heart disease following open-heart surgery. Pediatr Cardiol 2006;27:209-216.

-13 Reynolds EW, Ellington JG, Vranicar M, Bada HS: Brain-type natriuretic peptide in the diagnosis and management of persistent pulmonary hypertension of the newborn. Pediatrics 2004;114:1297-1304.

14 Moriichi A, Cho K, Mizushima M, Furuse Y, Akimoto T, Yamada T, Minakami H: B-type natriuretic peptide levels at birth predict cardiac dysfunction in neonates. Pediatr Int 2012;54:89-93.

15 Flynn PA, da Graca RL, Auld PA, Nesin M, Kleinman CS: The use of a bedside assay for plasma B-type natriuretic peptide as a biomarker in the management of patent ductus arteriosus in premature neonates. J Pediatr 2005; $147: 38-42$.

16 Chakkarapani E, Thoresen M, Liu X, Walloe L, Dingley J: Xenon offers stable haemodynamics independent of induced hypothermia after hypoxia-ischaemia in newborn pigs. Intensive Care Med 2012;38: 316-323. 